\title{
Challenges of Measuring Revenue, Margin and Yield Optimization in Container Shipping*
}

\author{
Albert Gardon ${ }^{1}$, Peter Nielsen $^{2}$, and Niels Gorm Malý Rytter ${ }^{3}$ \\ 1 Wrocław University of Economy, Komandorska 118/120, 53-345 Wrocław, Poland, \\ Fibigerstræde 16, 9220 Aalborg East, Denmark \\ Albert.Gardon@ue.wroc.pl \\ 2 Aalborg University, Fibigerstræde 16, 9220 Aalborg East, Denmark \\ peter@m-tech.aau.dk \\ 3 Aalborg University in Copenhagen, Lautrupvang 1A, 2750 Ballerup, Denmark \\ i9nr@m-tech. aau. dk
}

\begin{abstract}
We present in this paper some initial ideas of Revenue and Yield Management in the container shipping industry, namely a regression study of the behavior of the currently used indicator for measuring pricing and revenue performance in a leading shipping line. We consider the properties of the indicator used and discuss options of developing a better indicators of revenue or yield optimization, being either revenue or yield per available unit. At the end we also formulate implications for a future research work to be done on development of relevant measures for the industry.
\end{abstract}

Keywords: yield (revenue) management, liner shipping, transportation logistics.

\section{Introduction}

The aim of this paper is to provide a discussion what would constitute a reasonable measure for revenue or yield optimization in the container shipping industry. It reveals some initial ideas about Revenue (RM) or Yield Management (YM) applied in this business. The discipline of RM or YM has had widespread attention in a number of consumer oriented businesses (see [4 6 ] and [10]) as e.g. passenger airlines (see [3]), hotels, car rental companies and less in cargo transportation businesses for air cargo (see [9]), rail cargo, container shipping or road transport companies. Cargo businesses meet characteristics of importance for practicing RM of YM as fixed capacity, high fixed and low variable costs, time-variable or stochastic demand, segmentable markets and clients, perishable inventory or capacity and in advance selling services (see [2]). However, when addressing RM or YM in the container shipping industry, one must first realize that the industry might have similarities, but also differs from e.g. passenger and cargo airlines and their business conditions where most research and practical experience has been accumulated over many years, which makes it necessary to

* The Research was Conducted During the Author's Stay at Aalborg University.

C. Emmanouilidis, M. Taisch, D. Kiritsis (Eds.): APMS 2012, Part II, IFIP AICT 398, pp. 654-661, 2013.

(C) IFIP International Federation for Information Processing 2013 
tailor solutions and measures to the particular industry in focus. This paper addresses a particular case company in container shipping and investigates options for developing measures tailored to its business needs.

The remaining part of the paper is structured in two parts. First, we investigate with use of regression analysis the behavior of the currently used measure (indicator) for revenue optimization. Next, we discuss potential alternatives for developing one more indicator better suited to its business needs. Finally, a conclusion is made on required further effort to succeed with a better profitability indicator measuring the container shipping industry.

\section{Revenue Per Transported Unit and Related Behavior}

The first problem faced is the manner of the business condition reporting. In the container shipping industry the dominating revenue or yield optimization measure is the average price (called the net freight or the revenue) per unit sold (e.g. FFE - Forty Foot Equivalent, i.e. the volume of a 40 feet long container or TEU - Twenty-Foot Equivalent Unit, i.e. the volume of a 20 feet long container 1 ) reported every week. This is by industry standards considered to be a solid indicator of the company or market condition (see [7]). To investigate the behavior of this indicator and identifying the causes of its weekly variation we conducted a study at one of major container shipping lines. The study depended only on information about cargo typ 2 , transportation direction 3 , client typ 4 and operational region. We construct a linear regression model describing the behavior of the average net freight per FFE $(Y)$ as the dependent variable, namely:

$$
\widehat{Y}\left(X_{1}, \ldots, X_{k}\right)=\alpha_{0}+\sum_{i=1}^{k} \alpha_{i} X_{i},
$$

where $\widehat{Y}$ is the approximation of the average net freight per FFE (the dependent variable), $\left(X_{i}\right)_{i=1}^{k}$ are independent, explanatory variables and $\left(\alpha_{i}\right)_{i=0}^{k}$ are regression coefficients. Using only three independent variables, namely the ratio of a transported reefer and dry cargo (in FFE), the ratio of a transported cargo in the headhaul and backhaul direction (in FFE) and the ratio of a transported cargo in the most profitable (over the company average) and the least profitable (under the company average) regions (in FFE), we have explained around $85 \%$ of the weekly indicator volatility. From the study it is clear that

\footnotetext{
${ }^{1}$ Obviously 1 FFE $=2$ TEU.

2 There are two basic cargo types: reefer and dry. Reefer cargo requires containers keeping special atmosphere conditions, as low temperature, proper humidity, air circulation, which need to be pluged in. Dry cargo is shipped in ordinary containers without any additional requirements.

3 The direction, which the greater amount of containers is shipped in, is called the headhaul, whereas the opposite direction is called the backhaul.

${ }^{4}$ Client types differ in companies, but usually there is a group of the most important contractors which we will call the key clients.
} 
the most significant factor is the direction, because of the trade imbalances, i.e. a significantly lower demand for cargo transportation in one of directions, results in an essential number of empty containers transported in the backhaul direction. The less important has been the average region profitability, probably because of the strong inside price variation. Interestingly, replacing this variable by the amount of transported FFE's from only one properly chosen region gives a similar goodness of fit. This choice has been based on the observation that the amount of cargo shipped in this region has been almost uncorrelated with two other significant independent variables. However, both the more/less profitable

\begin{tabular}{|c|c|c|c|c|c|}
\hline SUMMARY OUTPU & & & & & \\
\hline \multicolumn{6}{|c|}{ Regression Statistics } \\
\hline Multiple R & 0,856548169 & & & & \\
\hline R Square & 0,733674765 & & & & \\
\hline Adjusted R Square & 0,72416315 & & & & \\
\hline Standard Error & 81,64210919 & & & & \\
\hline Observations & 59 & & & & \\
\hline \multicolumn{6}{|l|}{ ANOVA } \\
\hline & $d f$ & SS & MS & $F$ & Significance $F$ \\
\hline Regression & 2 & 1028271,319 & 514136 & 77,1346 & $8,15727 \mathrm{E}-17$ \\
\hline Residual & 56 & 373264,3036 & 6665,4 & & \\
\hline Total & 58 & 1401535,622 & & & \\
\hline
\end{tabular}

Fig. 1. The result of a linear regression model fitting (2 variables)

regions ratio and the cargo percentage from the chosen region have got a faint business sense, therefore we have omitted these. Nevertheless, the remaining two independent variables:

$$
\widehat{Y}\left(X_{1}, X_{2}\right)=\alpha_{0}+\alpha_{1} X_{1}+\alpha_{2} X_{2},
$$

i.e. the direction ratio $\left(X_{1}\right)$ and the cargo type ratio $\left(X_{2}\right)$ still give a satisfying goodness-of-fit which exceeds $70 \%$, as shown in the table from Fig 1

Unfortunately, further investigations have shown that the model fitted above for the company overall cannot be generalized for chosen parts of the business. The trouble is not only with an unstable goodness-of-fit, but in fact, similar analysis for chosen regions have given different adjusted squared Pearson correlation coefficients. In the worst case this drops even below 25\%, making the model completely unuseful in that instance. Although, in some cases the fitting is improved to around $70 \%$ by addition of other independent variables, as e.g. the percentage of FFE transported from key clients. What is more, it is observed that sometimes variables which are very important for one part of the business are at the same time completely insignificant for another part. This is a serious issue, since the model is not universal one needs to make separate studies for every instance. Although this is conlcuded for only one shipping line, we 
assume this to be a global phenomenon similar for all companies operating in this industry. Further studies of this will focus on other aspects of the business, especially lower levels of aggregation but using reacher data sets with many additional variables, also market data as e.g. Shanghai Containerized Freight Index (SCFI), whose development is shown in Fig, 2

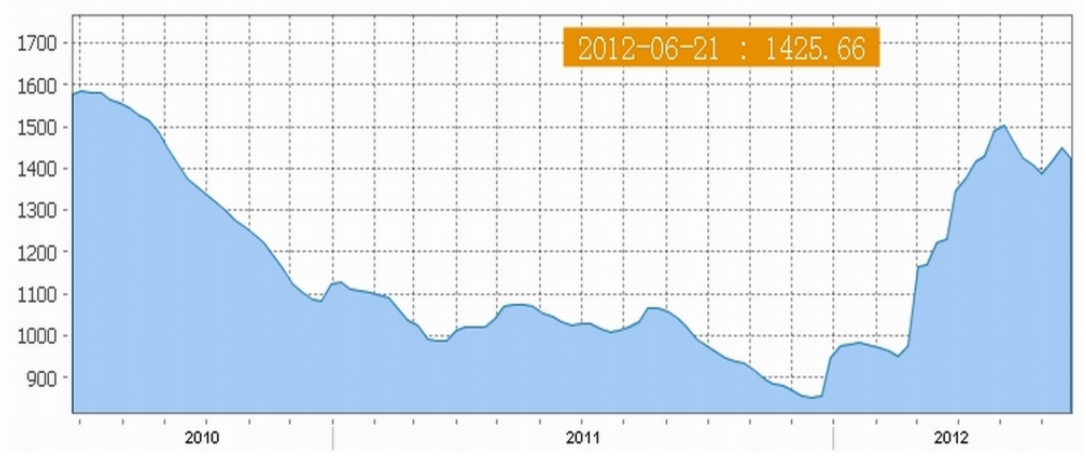

Fig. 2. Shanghai Containerized Freight Index (source: [11])

We must also add that this model is useful only in an explanatory sense, not as a predictive tool. First of all because the descriptive variables depend on the market demand and therefore are not immediately drivable by the shipping company. Besides, the values of these variables are observed only in quite short intervals, i.e. their standard deviations have been quite small, which implies the fit of the linear model could be doubtful for arguments which differ significantly from the mean values. The behavior of the indicator outside these intervals remains an open question.

\section{Weaknesses of the Existing Revenue Measure}

Having studied the currently used indicator we move forward to discuss what would be a better indicator for the revenue or yield optimization in this business. But what is more, and maybe the most important, the indicator mentioned in the previous section is maybe a critical parameter that cannot be omitted since it indicates market conditions, but in itself is not an adequate measure of how well the business is going. A company should not be satisfied (or dissatisfied) only because of increasing (or decreasing) prices. There should be incorporated somehow at least also such factors as e.g. the costs, the utilization (or capacity availability), i.e. the demand related to a changed service price, and the seasonality, i.e. comparison to results from previous years in a similar part of a year. This is what is done in e.g. the passenger airline industry (see [2]) and other industries further advanced in YM. Also better measures are a prerequisite for more advanced studies and prediction modelling (see [8]). 
Costs could in fact be neglected if they are constant over time (something that may the case for e.g. the hotel industry), but in fact they are not. However, the freight rate is compensated for some of these changing costs in the form of surcharges, e.g. bunker surcharge (BAF), that also varies over time (see Fig 3), so an increase of prices could be caused only by a cost increase which would not improve the business results. For this reason the indicator should ideally be based on a variable which includes costs of operations, e.g. a type of yield 5 .

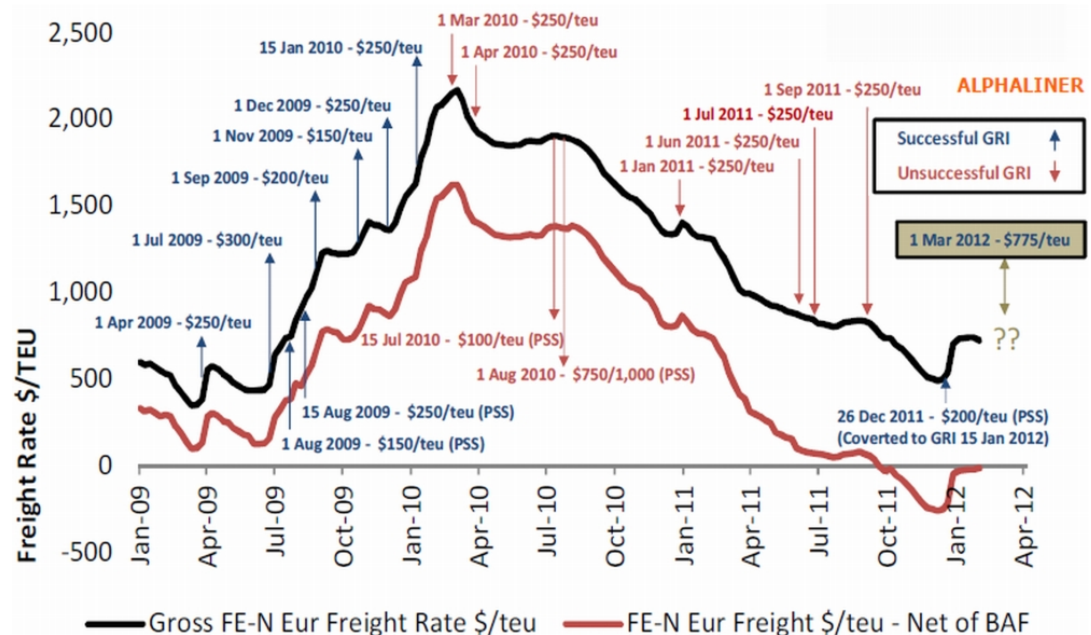

Fig. 3. Far East-North Europe spot rates (with and without bunker surcharge) vs rate increase announcements: 2009-2012 (source: [1])

Similarly, a reduction of prices does not necessarily result in worse company conditions, if at the same time the volume increases one could observe a higher total revenue, which means a better business situation due to economics of scale. An increase of the transport capacity should reduce unit costs at the same utilization which means a better yield. The conclusion despite volumes going up, means that a company in fact can have a higher revenue and due to economics of scale (with higher capacity vessels) a better total yield. However, the net freight per FFE would not show this. What is more, despite the unit price is one of the most significant variables affecting the total yield, though, a strong positive linear correlation between it and the yield is doubtful because higher prices usually imply higher yield only as long as the price increases are accepted by customers and do not result in lowering of volumes. For this reason the indicator should not be calculated just per units sold but per all capacity units available.

\footnotetext{
${ }^{5}$ The revenue after the subtraction of costs is called the margin, whereas the yield is the margin after the addition of the so-called flow adjustment linked to the empty containers evacuation.
} 
Finally, in order to find out if a company has an increasing or a decreasing trend of earnings one needs to compare the results to those from analogous time from previous years. This is especially critical for the liner shipping industry, as it is highly seasonal. If the yield behaves similarly as in the same season in previous years, its increase (or decrease) in comparison to the preceding observation time does not necessarily mean it is better (or worse) at the given time. Therefore it is necessary to compensate the company condition indicator for the seasonality. There are such times in the year when the demand decreases to a half or increases twice, e.g. Chinese New Year which lasts about two weeks and occurs from the middle of January to the middle of February, depending on the year. The problem becomes one of obtating enough historical data to model accurately the seasonality. This is an industry issue, because the industry is continuously changing the network structure, routings, capacities etc., making historical analysis and comparisons difficult at best. This problem is compounded in time, so that the further back in historical observation one would like to go, the worse the problem is. This motivates the usage of relatively new data, at most a few years old. Nevertheless, if such an approach will be provided the situation will improve in time because of a constant collection of the new data pouring in.

\section{The Proposed New Yield Optimization Measure}

When implementing RM or YM in an industry or a company, a choice of a main measure for revenue or yield optimization must be made. In consumer oriented businesses there is a tendency to emphasize revenue, where there in cargo oriented businesses is a focus on optimizing yield instead (see [9]), as different products and services also incur different variable costs depending e.g. on routing of cargo. Additionally, in container shipping we also need to cater for flow of empty containers (flow adjustment) due to cargo imbalances, which is also important in such a company. To sum up, we have proposed a new improved business indicator which takes into account all the factors mentioned in the previous section and should describe more precisely the company condition:

$$
J_{i}(t)=\frac{V_{i}(t)}{C_{i}(t)} \quad\left[\frac{\mathrm{USD}}{\mathrm{FFE}}\right],
$$

where $t$ is the departure time from a crucial port in the service (the so-called bottleneck port), $V_{i}(t)$ is the total yield [USD] from the $i$-th vessel at $t$ and $C_{i}(t)$ is the capacity available [FFE] on the $i$-th vessel at $t$. Incorporating the seasonality into the model we improve the indicator $J$ to $J^{*}$ :

$$
J_{i}^{*}(t)=S(t) J_{i}(t) \quad\left[\frac{\mathrm{USD}}{\mathrm{FFE}}\right],
$$

where $S(t)$ [no unit] is the seasonality factor at time $t$.

Since the capacity on a vessel is shared usually over more than one string6, at the first step we will focus on services. This is not a perfect approach, because

\footnotetext{
${ }^{6}$ A string is a virtual part of the network using a given amount of vessels capacity from one or more services.
} 
the business-wise thinking is in terms of strings, but a service is a physical part of business with the precisely defined number of vessels (undertaking roundtrips), the capacity and the departure intensity. On the other hand the yield is calculated for each booking separately and the booking is linked to a string rather than to a service. The perfect solution would be a calculation of the total yield for each sea trip (port to port), taking into account the inland delivery to the first loading port, loadings and discharges and the inland delivery to the receiver. Knowing it would enable to divide the yield from each cargo not only between services, but also between strings. But it seems to be unrealistic since tracebility of costs is typically not possible for all parts of the transportation process. Therefore the idea is to begin with the simplest cases and further systematically consider the problem in a more complex way, fitting the model as good as possible to the business reality and be able to calculate the indicator for more and more parts of the business.

At the first step we want to consider the simplest case, that means to select such services which are adapted to single strings in the sense that all capacity in a bottleneck port (separatelly in each direction) belongs to only one string. The next step will be to find such services which are adapted to more than one string, but all those strings have got only one bottleneck port in this chosen service. In this instance we will need weights for the capacity division $C_{i}$ over strings. This is a difficult task because the capacity on the vessel is not phisically signed for each string. What is more, it varies in time and sometimes is even exchanged by string managers. But it seems to be quite objective approach to use a discrete distribution of the slot division over strings, estimated on the basis of the historical data, for ordering the capacity available into the strings. The next step will be the calculation of the indicator for other strings which use more than one service (have got more than one bottleneck port). Now the yield $V_{i}$ needs to be divided additionally between different services (different bottleneck ports). Again we need a weight for this operation. This could be the percentage of the transportation time in days of the cargo within each service. It seems to be a reasonable choice because costs depend mainly on the transportation time (fuel, ports) and, besides, time spans are easy to identify since all departure and arrival dates are known. The last step will be the choise of the time window (day, week) and the decision concerning the level of aggregation, that means the decision which strings or services should be consider jointly, e.g. a geographical accumulation.

\section{Conclusions}

Using this new provided indicator we would like to investigate the impact of some central steering tools on the business. The two most popular are general rate increases (GRI) and capacity changes (allocation of vessels or addition of new vessels). Until now these effects have at many instances recently been invisible when observing the mean net freight per FFE (see Fig 3). This has by industry typically been interpreted as a lack of effect of GRIs. However, this 
may be a faulty assumption, since the current measure is not necessarily sensitive to GRIs like a utilization based measure should be. Regarding the GRI's the possible cause could be the fact that they are maybe announced centrally, but implemented locally and local managers maintain new higher price offers very often only for a quite short time if at all, which implies the average net freight per transported FFE remains almost unchanged. Although, it is a well known fact that the GRIs causes an increased demand in the time span (several weeks) between the announcement and the implementation, which improves the company condition and should be shown by the measure. On the other hand, the capacity increase by the higher demand should lead to profit increase even though at the same time a special lower price would be offered for certain group of customers. In such case a decrease in a mean net freight per transported FFE could be observed when the company condition would be improved. And finally, we want to construct a stochastic model, in the sense of a time series or even time continuous stochastic process, for our new indicator for predictive purposes.

Acknowledgement. This research was funded by the Danish Maritime Fund, through grant no. 2011-58.

\section{References}

1. Weekly Newsletter. Alphaliner (June 2012)

2. Belobaba, P., Barnhart, C., Odoni, A.: The Global Airline Industry. John Willey and Sons Ltd., Croydon (2009)

3. Chiang, W.C., Chen, J.C.H., Xu, X.: An Overview of Research on Revenue Management: Current Issues and Future Research. International Journal of Revenue Management 1(1), 97-128 (2007)

4. Kimes, S.E.: Yield Management: A Tool for Capacity-Constrained Service Firms. Journal of Operations Management 8(4), 349-363 (1989)

5. Levinson, M.: The Box - How the Shipping Container Made the World Smaller and the World Economy Bigger. Princeton University Press, New Jersey (2006)

6. McGill, J., van Ryzin, G.: Revenue Management: Research Overview and Prospects. Transportation Science 33(2), 233-256 (1999)

7. Stopford, M.: Maritime Economics. Routledge, London (2009)

8. Talluri, K.T., van Ryzin, G.J.: The Theory and Practice of Revenue Menagement. Springer, New York (2005)

9. Yeoman, I., McMahon-Beattie, U. (eds.): Revenue Management: A practical Pricing Perspective. Palgrave Macmillan, New York (2011)

10. Zurheide, S., Fischer, K.: A simulation study for evaluating a slot allocation model for a liner shipping network. In: Böse, J.W., Hu, H., Jahn, C., Shi, X., Stahlbock, R., Voß, S. (eds.) ICCL 2011. LNCS, vol. 6971, pp. 354-369. Springer, Heidelberg (2011)

11. Chineseshipping, http://www1.chineseshipping.com.cn/en/indices/scfi.jsp 